\title{
Modeling, simulation and optimal control strategy for batch fermentation processes
}

\author{
Neba Fabrice Abunde ${ }^{1,3} \cdot$ Nana Yaw Asiedu $^{2} \cdot$ Ahmad Addo $^{1}$
}

Received: 4 December 2017 / Accepted: 3 February 2019 / Published online: 18 February 2019

(c) The Author(s) 2019

\begin{abstract}
The use of fermenters at large scale is usually hampered by sub-optimal conditions in terms of yield and productivity, along with the low tolerance of strains to process stresses, such as substrate and product toxicity, and other fermentation inhibitors. Attempts to improve the industrial efficacy of fermenters have been in the areas of genetic engineering to improve strain tolerance, but this usually involves detailed and unfeasible mechanistic studies. Statistical designs of experiments have also been used to optimize industrial fermenters but this again often results in local optima due to the relatively small-dimensional space covered by the experiments. Mathematical techniques have recorded great successes and regarding ethanol fermentation with sorghum extracts, previous work has modeled and established the presence of product inhibition, however, did not consider other degrees of freedom (temperature and $\mathrm{pH}$ ) that minimize the effect of such inhibitions. This paper includes the description of a batch alcohol fermentation process that has been optimized using a technique based on the application of mathematical modeling and optimal control. Calculus of variation is introduced as a valuable tool to derive and solve the necessary conditions for optimality, and the obtained results show the optimal temperature and $\mathrm{pH}$ profiles for the fermentation of sorghum extracts. A Simulink model of the fermentation process shows that using the proposed control strategy increases ethanol yield by $14.18 \%$, cell growth by $71.96 \%$ decreases the residual substrate by $84.77 \%$.
\end{abstract}

Keywords Alcoholic fermentation · Mathematical modeling · Ethanol inhibition · Optimal control simulation · Sorghum extracts

\section{List of symbols}

$E_{\mathrm{g}} \quad$ Activation energy for cell growth (cal/mol)

$G_{\mathrm{s}} \quad$ Yield coefficient of cell based on substrate utilization $(\mathrm{g} / \mathrm{gh})$

$K_{\text {ip }} \quad$ Product inhibition coefficient on product formation $(100 \mathrm{~g} / \mathrm{g})$

$K_{\text {sp }} \quad$ Substrate saturation (Monod) constant for product formation $(\mathrm{g} / 100 \mathrm{~g})$

$K_{\text {sx }} \quad$ Substrate saturation (Monod) constant for cell growth $(\mathrm{g} / 100 \mathrm{~g})$

Nana Yaw Asiedu

nasiedusoe@yahoo.co.uk

1 Department of Agricultural and Biosystems Engineering, Kwame Nkrumah University of Science and Technology, Kumasi, Ghana

2 Department of Chemical Engineering, Kwame Nkrumah University of Science and Technology, Kumasi, Ghana

3 Department of Civil and Environmental Engineering, Norwegian University of Science and Technology, Trondheim, Norway
$M_{\mathrm{p}} \quad$ Specific rate of ethanol production by a maintenance metabolism (g/g h)

$M_{\mathrm{s}} \quad$ Specific rate of substrate consumption for cell maintenance $(\mathrm{g} / \mathrm{g} \mathrm{h})$

$T_{\max } \quad$ Maximum fermentation temperature $\left({ }^{\circ} \mathrm{C}\right)$

$T_{\min } \quad$ Minimum fermentation temperature $\left({ }^{\circ} \mathrm{C}\right)$

$Y_{\mathrm{p}} \quad$ Yield coefficient of cell based on substrate utilization $(\mathrm{g} / \mathrm{g})$

$Y_{\mathrm{x}} \quad$ Yield coefficient of cell based on substrate utilization $(\mathrm{g} / \mathrm{g})$

$k_{1} \quad$ Empirical constant in $\mathrm{pH}$ model $(\mathrm{mol} / \mathrm{l})$

$k_{2} \quad$ Empirical constant in $\mathrm{pH}$ model $(\mathrm{mol} / \mathrm{l})$

$k_{\mathrm{d}} \quad$ Cell death rate $\left(\mathrm{h}^{-1}\right)$

$k_{\mathrm{g}} \quad$ Pre-exponential Arrhenius constant for growth

$\mathrm{pH}_{\max }$ Maximum $\mathrm{pH}$ in the fermenter

$\mathrm{pH}_{\text {min }}$ Minimum $\mathrm{pH}$ in fermenter

$q_{\max } \quad$ Maximum specific rate of product formation $\left(\mathrm{h}^{-1}\right)$

$q_{\mathrm{p}} \quad$ Specific rate of product formation $\left(\mathrm{h}^{-1}\right)$

$\mu_{\max } \quad$ Maximum specific growth rate $\left(\mathrm{h}^{-1}\right)$

A Weight coefficient for product formation in optimization problem (dimensionless) 
$B \quad$ Weight coefficient for temperature control in optimization problem (dimensionless)

C Weight coefficient for $\mathrm{pH}$ control in optimization problem (dimensionless)

$J \quad$ Performance index for optimal control problem

$P \quad$ Concentration of product $(\mathrm{g} / 100 \mathrm{~g})$

$R \quad$ Universal gas constant (cal/K mol)

$S \quad$ Concentration of substrate $(\mathrm{g} / 100 \mathrm{~g})$

$X \quad$ Concentration of biomass (Mcells/0.1 ml)

$t \quad$ Batch fermentation time (h)

$T \quad$ Fermentation temperature $\left({ }^{\circ} \mathrm{C}\right)$

$\mu \quad$ Specific rate of cell growth $\left(\mathrm{h}^{-1}\right)$

\section{Introduction}

Sorghum, a cereal which belongs to the family Gramineae is now used in most breweries as locally available alternative to imported barley malt. In a generalized view of processing and brewing sorghum, though involves several unit operations, the fermentation step is the crux of the process, regarded as the heart of the entire production where a near optimal environment is desired for microorganisms to grow, multiply and produce the desired product [3]. However, the use of fermenters at a large scale is usually hampered by sub-optimal conditions in terms of yield and productivity, resulting from low tolerance of strains to process stresses, such as substrate and product inhibition, and other fermentation inhibitors $[10,14,17]$. In several attempts to improve the industrial efficacy of fermenters, a variety of approaches have been proposed; genetic techniques involving detailed, mechanistic studies of metabolic pathways, inherently involving inverse problem that cannot be understood with certainty [7]; statistical design of experiments [3], which again requires the construction of expensive prototype systems and most often leads to local optima due to the relatively small dimensional space covered by the experiments [3, 23].

Alternatively, design and optimization of bioreactors can be enhanced via validated mathematical models developed from mechanistic studies that lead to a more in depth understanding of process stresses such as ethanol inhibition [23]. In this regard, optimal temperature profiles have been determined to maximize beer flavor [19], maximize ethanol formation from sugarcane molasses (Marcus and Normey-Rico [13], minimize acetyl acetate production [9], maintain cell viability and reduce glycerol production [5]. However, the aforementioned as well as other studies have focused on temperature and rarely $\mathrm{pH}$ for optimization of batch fermentation processes. Fermentation principles consist of exploiting the metabolic reactions that take place in the cell of a microorganism for the production of valuable products [16]. To activate the metabolic pathways of interest within the cell, specific environmental conditions (temperature, $\mathrm{pH}$, nutrient concentration) are applied to enable the yeast cell grow and produce the required ethanol. In addition, due to the dynamic nature of the culture medium, yeast cells often suffer from various stresses resulting from both the environmental conditions, and from both product and or substrate imbibition [2]. To maximized ethanol yield, all the main aspect (ethanol inhibition kinetics, temperature and $\mathrm{pH}$ ) should be considered simultaneously [8]. This paper presents the optimal $\mathrm{pH}$ and temperature profiles in the alcoholic fermentation of sorghum extracts using a linear product inhibition model developed in our previous study [1]. Optimal profiles of temperature and $\mathrm{pH}$ are important in the control these stresses, flavor active compounds such as esters and in the control of these stresses, compounds such as esters and higher molecular mass alcohols can be maximized which can lead to increase in alcohol (ethanol) yield [20, 22].

\section{Bioreactor modeling and parameter estimation}

The Monod equation for cell growth and product formation, respectively, was chosen to describe the kinetics of cell growth and product formation, as given in the following equation:

$\mu(S)=\frac{\mu_{\max } S}{K_{\mathrm{sx}}+S}$,

$q_{\mathrm{p}}(S)=\frac{q_{\mathrm{max}} S}{K_{\mathrm{sp}}+S}$.

In our previous study [1], we proposed a simple linear factor to describe product inhibition in the alcoholic fermentation of sorghum extracts, expressed as

$f=\left(1-K_{\mathrm{ip}} P\right)$.

Introducing this effect on the specific rate of product formation, Eq. (1b) becomes

$q_{\mathrm{p}}(S)=\frac{q_{\mathrm{max}} S}{K_{\mathrm{sp}}+S}\left(1-K_{\mathrm{ip}} P\right)$.

The dynamic equations describing the cell growth, product formation and substrate utilization were developed by applying the principle of conservation of mass, resulting in the systems of first-order ordinary differential equations presented in Eqs. (4a, 4b, 4c). The change in substrate concentration depends on four terms: substrate assimilation into biomass 
$\left(\mu X / Y_{\mathrm{X}}\right)$, substrate assimilation into extracellular product $\left(q X / Y_{\mathrm{p}}\right)$, substrate utilization for cell growth $\left(G_{\mathrm{s}} X\right)$ and substrate utilization for maintenance energy $\left(M_{\mathrm{s}} X\right)$.

$\frac{\mathrm{d} X}{\mathrm{~d} t}=\mu X-k_{\mathrm{d}} X$,

$\frac{\mathrm{d} P}{\mathrm{~d} t}=q X+M_{\mathrm{p}} X$

$\frac{\mathrm{d} S}{\mathrm{~d} t}=-\frac{\mu X}{Y_{\mathrm{x}}}-\frac{q X}{Y_{\mathrm{p}}}-G_{\mathrm{s}} X-M_{\mathrm{s}} X$.

Introducing the expressions for $\mu$ and $q$ from Eqs. (1a) and (3), Eqs. (4a, 4b, 4c) becomes

$\frac{\mathrm{d} X}{\mathrm{~d} t}=\frac{\mu_{\max } S}{K_{\mathrm{sx}}+S} X-k_{\mathrm{d}} X$,

$\frac{\mathrm{d} P}{\mathrm{~d} t}=\left(1-K_{\mathrm{ip}} P\right) \frac{q_{\mathrm{max}} S}{K_{\mathrm{sp}}+S} X+M_{\mathrm{p}} X$,

$\frac{\mathrm{d} S}{\mathrm{~d} t}=-\frac{\mu X}{Y_{\mathrm{x}}}-\frac{q X}{Y_{\mathrm{p}}}-G_{\mathrm{s}} X-M_{\mathrm{s}} X$.

\section{Optimal control problem formulation}

The objective of the control is to determine the optimal temperature and $\mathrm{pH}$ profiles that will minimize the effect of ethanol inhibition on cell growth and hence maximize ethanol yield at the end of fermentation. The temperature dependency of the cellular activity was modeled using the following Arrhenius-like equation:

$\mu=f\left\{\left[\mu_{\max } \exp \left(-\frac{E_{\mathrm{g}}}{\mathrm{RT}}\right)\right]\right\}$,

$k_{\mathrm{d}}=f\left\{\left[k_{\mathrm{d}} \exp \left(-\frac{E_{\mathrm{g}}}{R T}\right)\right]\right\}$.

Typical values for these parameters were taken from the literature [21].

A typical term, Eq. (7) that accounts for $\mathrm{pH}$ dependence was also introduced into the specific growth rate expression.

Although this simple model cannot possibly explain $\mathrm{pH}$ dependence, the literature shows that it gives an adequate fit for many microorganisms [15]. The additional term is in the following form:

$\mu=f\left(\frac{\mu_{\max }}{1+\frac{k_{1}}{10^{-\mathrm{pH}}}+\frac{10^{-\mathrm{pH}}}{k_{2}}}\right)$.
The values of $k_{1}$ and $k_{2}$ that were used for the numerical simulations are chosen to be in their typical ranges from the literature [15, 21]. Introducing the effect of temperature and pH into Eqs. (5a, 5b, 5c), we arrive at the following system of differential equation:

$\frac{\mathrm{d} X}{\mathrm{~d} t}=\frac{\mu_{\mathrm{max}} k_{\mathrm{g}} \exp \left(-\frac{E_{\mathrm{g}}}{R T}\right)}{1+\frac{k_{1}}{10^{-\mathrm{pH}}}+\frac{10^{-\mathrm{pH}}}{k_{2}}} \frac{S}{K_{\mathrm{sx}}+S} X-k_{\mathrm{d}} \exp \left(-\frac{E_{\mathrm{g}}}{R T}\right) X$,

$\frac{\mathrm{d} P}{\mathrm{~d} t}=q_{\mathrm{max}}\left(1-K_{\mathrm{ip}} P\right) \frac{S}{K_{\mathrm{sp}}+S} X+M_{\mathrm{p}} X$,

$$
\begin{aligned}
\frac{\mathrm{d} S}{\mathrm{~d} t} & =\frac{-\mu_{\mathrm{max}} k_{\mathrm{g}} \exp \left(-\frac{E_{\mathrm{g}}}{\mathrm{RT}}\right)}{1+\frac{k_{1}}{10^{-\mathrm{pH}}}+\frac{10^{-\mathrm{pH}}}{k_{2}}} \frac{\mathrm{SX}}{Y_{\mathrm{x}}\left(K_{\mathrm{sx}}+S\right)} \\
& -\frac{q_{\mathrm{max}} S\left(1-K_{\mathrm{ip}} P\right) X}{Y_{\mathrm{p}}\left(K_{\mathrm{sp}}+S\right)}-X\left(G_{\mathrm{s}}+M_{\mathrm{s}}\right) .
\end{aligned}
$$

The optimal control problem to be maximized is then formulated with Eqs. (8a, 8b, 8c). The general objective of the optimal control problem is to determine the control signals (temperature and $\mathrm{pH}$ ) that will cause the controlled system (batch fermentation process) to satisfy the physical constraints (state equation, Eqs. (9b)-(9d) as well as temperature and $\mathrm{pH}$ bounds, Eqs. (9e) and (9f), at the same time, maximize the performance criterion $(J)$ ", which has been defined in the Lagrangian form, Eq. (9a). The performance criterion $(J)$ is a functional used for quantitative evaluation of a system's performance and can depend on both the control and state variables and on the initial and/or terminal times too (if not fixed) [12].

In this study, the final fermentation time is fixed and the performance criterion is formulated to depend only on the product concentration and the controlled variables.

Weights are introduced to differentiate the degree of dependence of the performance criterion on the state and controlled variables. The constants $A, B, C$ are the respective weights of the product (state to be maximized), temperature and $\mathrm{pH}$ (controlled variables). In this study, all the variables were assumed to have the same importance and the weights were all given a unit value.

$J=\int_{0}^{t_{f}}\left[A P^{2}+B \exp \left(-\frac{E_{\mathrm{g}}}{\mathrm{RT}}\right)+C\left(\frac{k_{1}}{10^{-\mathrm{pH}}}+\frac{10^{-\mathrm{pH}}}{k_{2}}\right)\right] \mathrm{d} t$,

s.t.

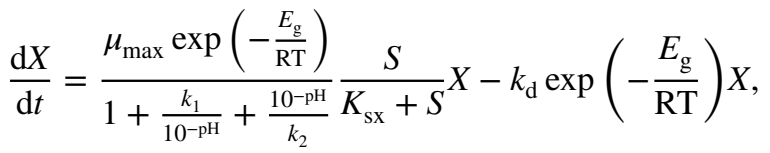


$\frac{\mathrm{d} P}{\mathrm{~d} t}=q_{\mathrm{max}}\left(1-K_{\mathrm{ip}} P\right) \frac{S}{K_{\mathrm{sp}}+S} X+M_{\mathrm{p}} X$,

$\frac{\mathrm{d} S}{\mathrm{~d} t}=\frac{-\mu_{\max } \exp \left(-\frac{E_{\mathrm{g}}}{\mathrm{RT}}\right)}{1+\frac{k_{1}}{10^{-\mathrm{pH}}}+\frac{10^{-\mathrm{pH}}}{k_{2}}} \frac{\mathrm{SX}}{Y_{x}\left(K_{\mathrm{sX}}+S\right)}$

$-\frac{q_{\mathrm{max}} S\left(1-K_{\mathrm{ip}} P\right) X}{Y_{\mathrm{p}}\left(K_{\mathrm{sp}}+S\right)}-X\left(G_{\mathrm{s}}+M_{\mathrm{s}}\right)$,

$T_{\min } \leq T(t) \leq T_{\max }$,

$\mathrm{pH}_{\min } \leq \mathrm{pH}(t) \leq \mathrm{pH}_{\max }$,

To facilitate subsequent mathematical manipulations of the objective function, we define the following transformations:

$x_{1}=X, \quad x_{2}=P, \quad x_{3}=S \quad p_{1}=\mu_{\max }, \quad p_{2}=q_{\max }$

$p_{3}=K_{\mathrm{sx}}, \quad p_{4}=K_{\mathrm{sp}}, \quad p_{5}=Y_{\mathrm{x}}, \quad p_{6}=k_{\mathrm{d}}$

$p_{6}=G_{\mathrm{s}}, \quad p_{7}=M_{s}, \quad p_{9}=M_{\mathrm{p}}, \quad p_{10}=K_{\mathrm{ip}} \quad p_{11}=Y_{\mathrm{p}}$

$u_{1}=\exp \left(-\frac{E_{\mathrm{g}}}{R T}\right), \quad u_{2}=\frac{k_{1}}{10^{-\mathrm{pH}}}+\frac{10^{-\mathrm{pH}}}{k_{2}}$

Replacing these variables into Eqs. (9a, 9b, 9c, 9d, 9e, 9f), we obtain the following equation:

$\operatorname{Max} J=\int_{0}^{t_{f}}\left[A x_{2}(t)^{2}+B u_{1}(t)^{2}+C u_{2}(t)^{2}\right] \mathrm{d} t$,

s.t.

$\frac{\mathrm{d} x_{1}}{\mathrm{~d} t}=\frac{p_{1}}{1+u_{2}} \frac{u_{1} x_{3}}{p_{3}+x_{3}} x_{1}-p_{6} u_{1} x_{1}$,

$\frac{\mathrm{d} x_{2}}{\mathrm{~d} t}=\left(1-p_{10} x_{2}\right) \frac{p_{2} x_{3}}{p_{4}+x_{3}} x_{1}+p_{9} x_{1}$,

$\frac{\mathrm{d} x_{3}}{\mathrm{~d} t}=\frac{-p_{1} u_{1}}{1+u_{2}} \frac{x_{3} x_{1}}{p_{5}\left(p_{3}+x_{3}\right)}-\frac{p_{2} x_{3}\left(1-p_{10} x_{2}\right) x_{1}}{p_{11}\left(p_{4}+x_{3}\right)}-x_{1}\left(p_{7}+p_{8}\right)$,

$u_{1 \min } \leq u_{1}(t) \leq u_{1 \max }$,

$u_{2 \min } \leq u_{2}(t) \leq u_{2 \max }$,

If the state, control, and static parameters can each be written in component form as

$x(t)=\left[\begin{array}{c}x_{1}(t) \\ \vdots \\ x_{3}(t)\end{array}\right] ; \quad u(t)=\left[\begin{array}{c}u_{1}(t) \\ \vdots \\ u_{2}(t)\end{array}\right] ; \quad p(t)=\left[\begin{array}{c}p_{1}(t) \\ \vdots \\ p_{10}(t)\end{array}\right]$ $f[x(t), u(t), t ; p]=\left[\begin{array}{c}f_{1}[x(t), u(t), t ; p] \\ \vdots \\ \left.f_{3}[x(t), u(t), t ; p]\right)\end{array}\right]$,

where

$f_{1}[x(t), u(t), t ; p]=\frac{p_{1}}{1+u_{2}} \frac{u_{1} x_{3}}{p_{3}+x_{3}} x_{1}-p_{6} u_{1} x_{1}$,
$f_{2}[x(t), u(t), t ; p]=\left(1-p_{10} x_{2}\right) \frac{p_{2} x_{3}}{p_{4}+x_{3}} x_{1}+p_{9} x_{1}$,

$f_{3}[x(t), u(t), t ; p]=\frac{-p_{1} u_{1}}{1+u_{2}} \frac{p_{5}^{-1} x_{3} x_{1}}{\left(p_{3}+x_{3}\right)}$

$$
-\frac{p_{2} x_{3}\left(1-p_{10} x_{2}\right) x_{1}}{p_{11}\left(p_{4}+x_{3}\right)}-x_{1}\left(p_{7}+p_{8}\right) \text {. }
$$

Then optimal control problem can be simply written as follows:

$\operatorname{Max} J(u)=\int_{t_{0}}^{t_{f}} \mathcal{L}[x(t), u(t), t ; p] \mathrm{d} t$.

Subject to

$\dot{x}(t)=f[x(t), u(t), t ; p]$

$u_{\min } \leq u(t) \leq u_{\max }$,

where $\mathcal{L}[x(t), u(t), t ; p]=\left[A x_{2}(t)^{2}+B u_{1}(t)^{2}+C u_{2}(t)^{2}\right]$

Referred to as the Lagrangian form of an optimal control problem.

\section{Solution technique by calculus of variations}

In an indirect method, calculus of variations is applied to determine the first-order optimality conditions first-order necessary conditions for an optimality conditions and the first-order necessary conditions for an optimal trajectory. These conditions can be obtained by using the augmented Hamiltonian $(H)$ defined by equation (17)

$H(x, \lambda, u, t ; p)=\mathcal{L}+\lambda^{\mathrm{T}} f$,

where $\lambda(t) \in \mathbb{R}^{n}$ is the costate or adjoint state. In the case of a single phase optimal control problem with no static parameters, the first-order optimality conditions of the continuoustime problem are given as follows:

$\dot{x}=\left[\frac{\partial H}{\partial \lambda}\right]^{\mathrm{T}}$,

$\dot{\lambda}=-\left[\frac{\partial H}{\partial x}\right]^{\mathrm{T}}$, 
$u^{*}=\arg \min _{u \in U} H$,

where $U$ is the feasible control set

The systems of differential equations presented in Eqs. (18a, 18b) are referred to as the Hamiltonian system, derived from the differentiation of a Hamiltonian [6, 11]. Furthermore, the optimal control profile to the system is determined from the application of the Pontryagin's minimum principle (PMP) resulting in Eq. (19) and this is the classical method of determining the control [18]. The Hamiltonian system, together with the boundary, transversality, is referred to as a Hamiltonian boundary-value problem (HBVP) $[4,6]$ and the solution to such a system is called an extremal.

Now applying calculus of variations to Eqs. (10a, 10b, 10c, 10d, 10e, 10f), the Hamiltonian can be written as follows:

$$
\begin{aligned}
& H=A x_{2}(t)^{2}+B u_{1}(t)^{2}+C u_{2}(t)^{2} \\
& +\lambda_{1}\left(\frac{p_{1} u_{1} x_{1}}{1+u_{2}} M-p_{6} u_{1} x_{1}\right) \\
& +\lambda_{2}\left(p_{2} N x_{1}+p_{9} x_{1}\right) \\
& +\lambda_{3}\left(\frac{-p_{1} u_{1} x_{1}}{1+u_{2}} \frac{M}{p_{5}}-\frac{p_{2} N x_{1}}{p_{11}}-x_{1}\left(p_{7}+p_{8}\right)\right),
\end{aligned}
$$

where $M=\frac{x_{3}}{p_{3}+x_{3}} \quad$ and $\quad N=\left(1-p_{10} x_{2}\right) \frac{x_{3}}{p_{4}+x_{3}}$.

\section{State equations}

If we differentiate the Hamiltonian, Eq. (17) with respect to the co-states, Eq. (18a), we obtain the following state equations:

$\frac{\mathrm{d} x_{1}}{\mathrm{~d} t}=\frac{p_{1}}{1+u_{2}} \frac{u_{1} x_{3}}{p_{3}+x_{3}} x_{1}-p_{6} u_{1} x_{1}$,

$\frac{\mathrm{d} x_{2}}{\mathrm{~d} t}=\left(1-p_{10} x_{2}\right) \frac{p_{2} x_{3}}{p_{4}+x_{3}} x_{1}+p_{9} x_{1}$

$\frac{\mathrm{d} x_{3}}{\mathrm{~d} t}=\frac{-p_{1} u_{1}}{1+u_{2}} \frac{x_{3} x_{1}}{p_{5}\left(p_{3}+x_{3}\right)}-\frac{p_{2} x_{3}\left(1-p_{10} x_{2}\right) x_{1}}{p_{11}\left(p_{4}+x_{3}\right)}-x_{1}\left(p_{7}+p_{8}\right)$,

\section{Costate equations}

If we differentiate the Hamiltonian, Eq. (17) with respect to the states, Eq. (18b), we obtain the following state equations:

$$
\begin{aligned}
& \frac{\mathrm{d} \lambda_{1}}{\mathrm{~d} t}=\lambda_{1}\left(p_{6} u_{1}-\frac{p_{1} u_{1} M}{1+u_{2}}\right)-\lambda_{2}\left(p_{9}+p_{2} N\right) \\
& +\lambda_{3}\left(\frac{p_{1} u_{1} M}{p_{5}\left(1+u_{2}\right)}+\frac{p_{2} N}{p_{11}}+p_{7}+p_{8}\right),
\end{aligned}
$$

$\frac{\mathrm{d} \lambda_{2}}{\mathrm{~d} t}=-2 A x_{2}+\frac{p_{2} p_{10} x_{1} N}{\left(1-p_{10} x_{2}\right)}\left(\lambda_{2}+\frac{\lambda_{3}}{p_{11}}\right)$

$$
\begin{aligned}
\frac{\mathrm{d} \lambda_{3}}{\mathrm{~d} t} & =-\lambda_{1}\left(\frac{p_{1}}{1+u_{2}}\right) p_{3} u_{1} Q-\lambda_{2} Z p_{4} p_{2} \\
- & \lambda_{3}\left(\frac{-p_{1} u_{1}}{1+u_{2}}\right)\left(\frac{p_{3} Q}{p_{5}}\right)+\lambda_{3} \frac{Z p_{4} p_{2}}{p_{11}},
\end{aligned}
$$

where $Q=\frac{x_{1}}{\left(p_{3}+x_{3}\right)^{2}} \quad$ and $\quad Z=\left(1-p_{10} x_{2}\right) \frac{x_{1}}{\left(p_{4}+x_{3}\right)^{2}}$.

\section{Optimal control equations}

The optimal control equations are obtained by applying the Pontryagin's minimum principles in Eqs. (17)-(15). The Hamiltonian gradient can be represented by differentiating the Hamiltonian with respect to the controls to obtain the following equations:

$\frac{\mathrm{d} H}{\mathrm{~d} u_{1}}=2 B u_{1}+\lambda_{1}\left(\frac{W}{1+u_{2}}-p_{6} x_{1}\right)-\lambda_{3} \frac{W}{p_{5}\left(1+u_{2}\right)}$,

$\frac{\mathrm{d} H}{\mathrm{~d} u_{2}}=2 C u_{2}-\lambda_{1} \frac{u_{1} W}{\left(1+u_{2}\right)^{2}}+\lambda_{3} \frac{u_{1} W}{p_{5}\left(1+u_{2}\right)^{2}}$,

$W=\frac{p_{1} x_{1} x_{3}}{p_{3}+x_{3}}$.

The necessary optimality conditions for a local maximizer are that this gradient should be equal to zero as shown by the following equations:

$2 B u_{1}^{*}+\lambda_{1}\left(\frac{W}{1+u_{2}^{*}}-p_{6} x_{1}\right)-\lambda_{3} \frac{W}{p_{5}\left(1+u_{2}^{*}\right)}=0$,

$2 C u_{2}^{*}+\frac{u_{1}^{*} W}{\left(1+u_{2}^{*}\right)^{2}}\left(-\lambda_{1}+\frac{\lambda_{3}}{p_{5}}\right)=0$.

The expressions for temperature and $\mathrm{pH}$ can then be written as Eqs. (25) and (26), respectively, and the optimal control trajectories become Eqs. (27) and (28).

$T=\frac{1}{R} \ln \frac{k_{g}}{u_{1}^{*}}$,

$\mathrm{pH}=\frac{1}{\ln 10} \ln \left(\frac{k_{2} u_{2}^{*}+\sqrt{\left(k_{2} u_{2}^{*}\right)^{2}-4 k_{1} k_{2}}}{2 k_{1} k_{2}}\right)$, 
$T^{*}=\min \left(T_{\max }, \max \left(T_{\min }, T\right)\right.$,

$\mathrm{pH}^{*}=\min \left(p H_{\max }, \max \left(p H_{\min }, p H\right)\right.$,

\section{Numerical simulations and control validation}

The states, costate and optimal control equations are referred to as the Hamiltonian boundary-value problem (HBVP) with boundary conditions given by the following equation:

$\lambda\left(t_{f}\right)=\left[\begin{array}{l}0 \\ 0 \\ 0\end{array}\right] \quad x\left(t_{0}\right)=\left[\begin{array}{c}0.1 \\ 0.7 \\ 16.8\end{array}\right]$.

A collocation method based on the Labatto IIIA formula was used to simulate the HBVP, and a Matlab code was written to implement this algorithm using the Matlab routine 'bvp4c'. The collocation polynomial provides a $\mathrm{C}^{1}$-continuous solution that is fourth-order accurate uniformly in [a b]. Mesh selection and error control are based on the residual of the continuous solution. The numerical solution for the necessary optimality conditions, Eqs. (24a, $24 b)$ is obtained using the Matlab routine 'fsolve', which finds the roots for systems of nonlinear equations. In validating the controls, the alcohol fermentation model described in section III was implemented in the SIMULINK environment. This implemented model includes the objective function to be maximized.

\section{Results and discussion}

Figures 1 and 2 present the optimal temperature and $\mathrm{pH}$ profiles optimize the fermentation process. Simulation using the Simulink model, Fig. 7 shows that the optimal temperature
Fig. 1 Optimal temperature profile

Fig. 2 Optimal pH profile
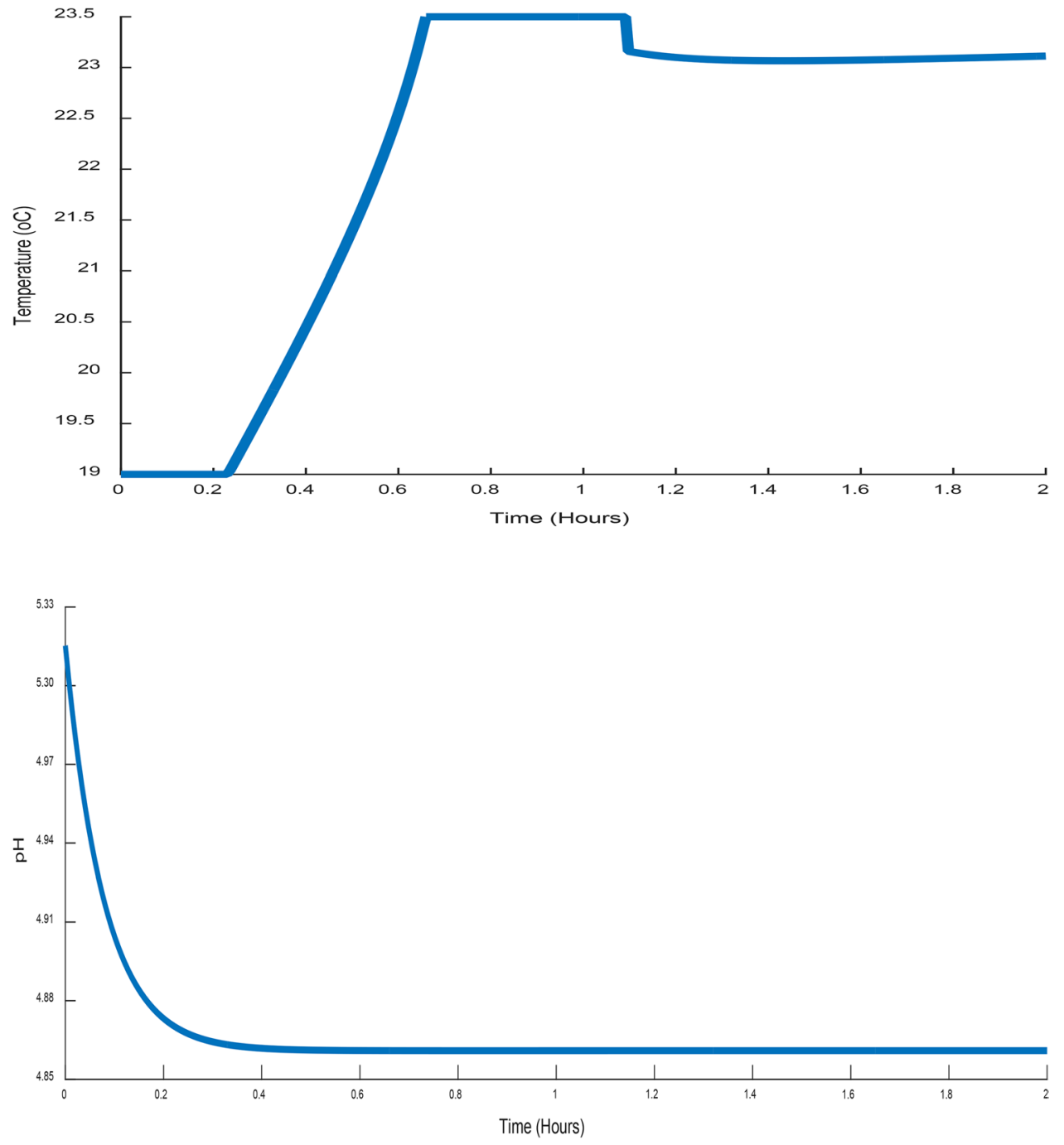
Table 1 Final states for optimal and conventional conditions

\begin{tabular}{lll}
\hline Final state & Optimal & Conventional \\
\hline Biomass $($ Mcells/0.1 ml) & 0.3219 & 0.1872 \\
Product $(\mathrm{g} / 100 \mathrm{~g})$ & 7.748 & 6.785 \\
Substrate $(\mathrm{g} / 100 \mathrm{~g})$ & 5.872 & 10.85 \\
Performance index & $5.593 \mathrm{e}+05$ & $5.455 \mathrm{e}+05$ \\
\hline
\end{tabular}

and $\mathrm{pH}$ profiles obtained an increment in cell growth of $71.96 \%$, product formation by $14.18 \%$ and substrate utilization by $84.77 \%$ compared to using the conventional temperature and $\mathrm{pH}$ values used by the industry. This improvement in process performance observed can be explained by the fact that due to the dynamic nature of the culture medium, yeast cells often suffer from various stresses resulting from both the environmental conditions, and from both product and or substrate imbibition as the fermentation proceeds.

Optimal profiles (and not constant values) of temperature and $\mathrm{pH}$ are important in the controlling these stresses, and ensure that the culture medium conditions stays constant, hence maximizing yield [20]. The increase in substrate utilization did not balance up with product formation because some of the substrate was utilized for cell growth and maintenance. Table 1 presents the values of the final states and
Fig. 3 Experimental and model results

Table 2 Simulated kinetic parameter values

Fig. 4 Dynamics of cell growth with optimal and conventional controls

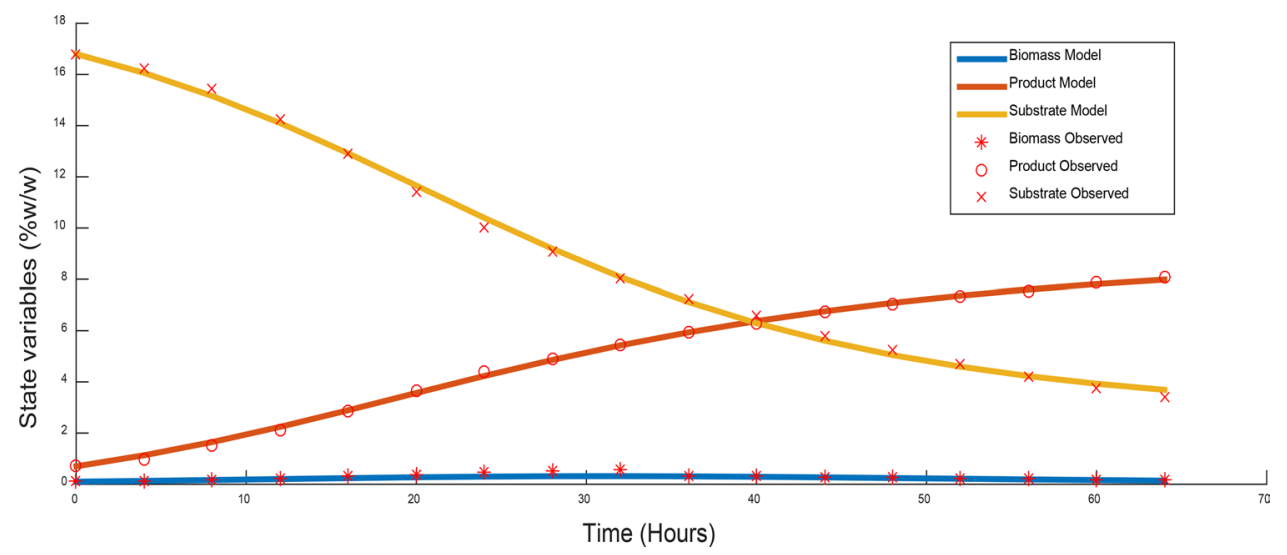

\begin{tabular}{llllllllllll}
\hline Parameter & $\mu_{\max }$ & $q_{p \max }$ & $k_{\mathrm{d}}$ & $m_{\mathrm{p}}$ & $K_{\mathrm{ip}}$ & $K_{\mathrm{sx}}$ & $K_{\mathrm{sp}}$ & $Y_{\mathrm{x}}$ & $Y_{\mathrm{p}}$ & $m_{\mathrm{s}}$ & $G_{\mathrm{s}}$ \\
\hline Value & 2.200 & 0.436 & 0.072 & 0.686 & 0.335 & 246.266 & 3.063 & 0.086 & 0.759 & 0.002 & 0.003 \\
Model error & $\mathbf{0 . 8 9 4 0}$ & & & & & & & & & & \\
\hline
\end{tabular}

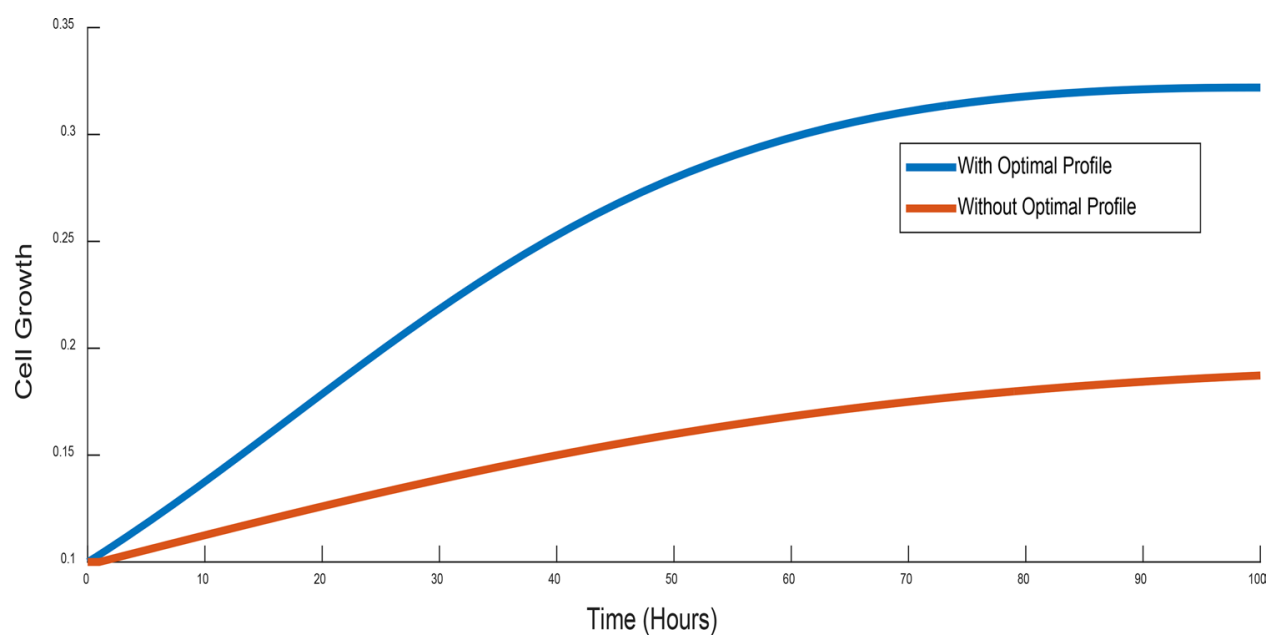


Fig. 5 Dynamics of product formation with optimal and conventional controls
Fig. 6 Dynamics of substrate utilization with optimal and conventional controls
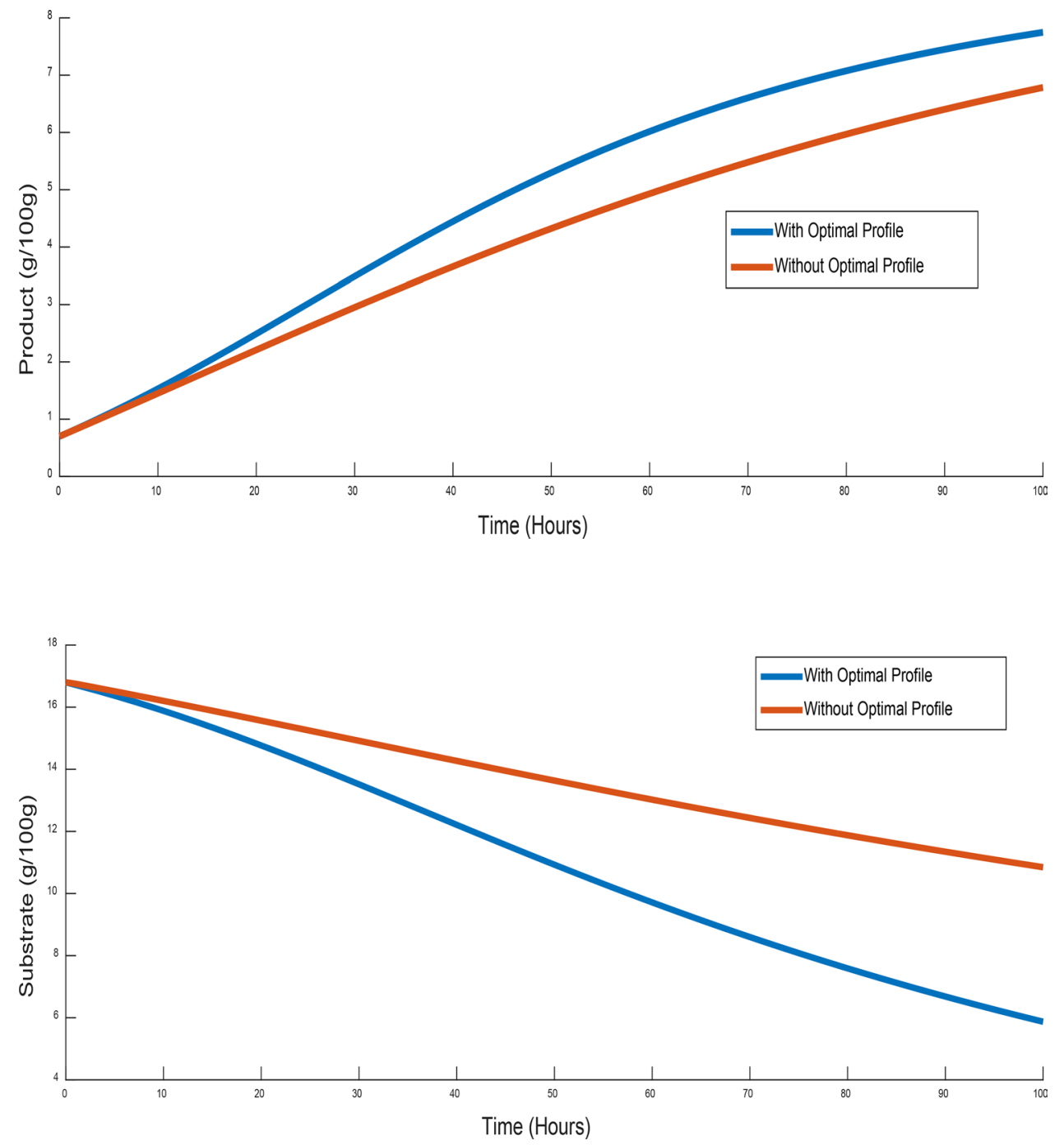

cost functional for both the Optimal and the conventional operation conditions. Figure 3 presents the fitting for the model taking into consideration the death rate and Table 2 the parameter values. Table 1 presents the values of the final states of both the optimal and conventional operation conditions. Figures 4, 5, 6, and 7 compare the optimal and conventional operating strategies, clearly depicting increase in process performance.

\section{Conclusion and recommendations}

This paper presented the modeling of a batch alcoholic fermentation process using sorghum extracts, followed by the application of optimal control to determine the optimal temperature and $\mathrm{pH}$ profiles that maximizes yield. Since the model was developed using industrial scale fermentation data, the results obtained in the simulations can satisfactorily represent a real operation unit. From the comparative results presented in the simulations, it is concluded that the proposed strategy can be used in practice to improve the performance of industrial scale alcoholic fermentation using sorghum. 


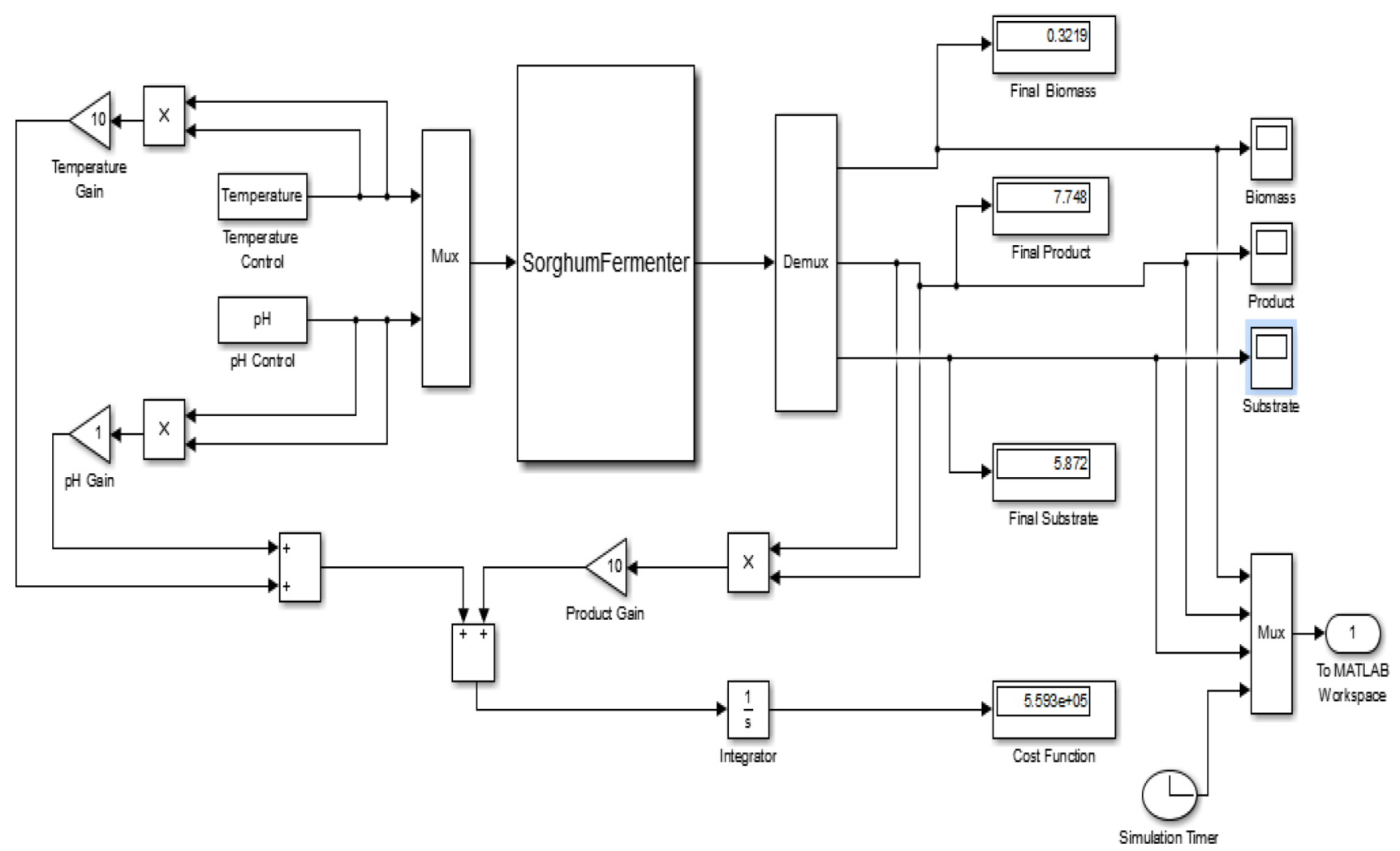

Fig. 7 Proposed Simulink Model for alcoholic fermentation of Sorghum Extract

Acknowledgements Our team expresses sincere thanks to Intra-ACP under the project "Strengthening African Higher Education through Academic Mobility", STREAM and to EnPe-NORAD under the project Upgrading Education and Research Capacity in Renewable Energy Technologies (UPERC-RET). Appreciation also goes to the following institutions: Some Breweries in Ghana for supplying us with industrial data for this work and the Brew-Hammond Energy Centre, KNUST Ghana.

Open Access This article is distributed under the terms of the Creative Commons Attribution 4.0 International License (http://creativeco mmons.org/licenses/by/4.0/), which permits unrestricted use, distribution, and reproduction in any medium, provided you give appropriate credit to the original author(s) and the source, provide a link to the Creative Commons license, and indicate if changes were made.

\section{References}

1. Abunde NF et al (2017) Dynamics of inhibition patterns during fermentation processes-Zea Mays and Sorghum Bicolor case study. Int J Indus Chem 8(1):91-99

2. Asiedu NY et al (2016) Modeling and simulation of substrate and product inhibitions of fermentation of cassava (Manihot Esculenta) extract. Indus Biotechnol 12(5):303-316

3. Alford JS (2006) Bioprocess control advances and challenges. Comput Chem Eng 30:1464-1475
4. Ascher UM, Mattheij RM, Russell RD (1996) Numerical solution of boundary-value problems in ordinary differential equations. SIAM Press, Philadelphia

5. Atala DIP, Costa AC, Maciel R, Maugeri F (2001) Kinetics of ethanol fermentation with high biomass concentration considering the effect of temperature. Appl Biochem Biotechnol 91-93:353-365

6. Athans MA, Falb PL (2006) Optimal control: an introduction to the theory and its applications. Dover Publications, Mineola

7. Brenner S (2010) Sequences and consequences. Philos T Roy Soc B 365:207-212

8. Carrillo-Ureta GE (2002) Optimal control of fermentation processes. PhD Thesis, City University, London, U.K

9. Carrilo-Uretha GE, Roberts PD, Becerra VM (2001) Genetic algorithm for optimal control of beer fermantation. In: Proc. IEEE International Symposium on Intelligent Control, Mexico, pp 391-396

10. Fischer CR, Klein-Marcuschamer D, Stephanopoulos G (2008) Selection and optimization of microbial hosts for biofuel production. Metab Eng 10:295-304

11. Leitman G (1981) The calculus of variations and optimal control. Springer, New York

12. Luus R (1990) Application of dynamic programming to highdimensional non-linear optimal control problems. Int J Control 52(1):239-250

13. Marcus V. Normey-Rico, J. E (2011) Modeling, Control and Optimization of Ethanol Fermentation Process. Preprints of the 18th IFAC World Congress Milano (Italy)

14. Naydenova V Iliev, Kaneva VM, Kostov G (2013) Modeling of alcohol fermentation in brewing-carbonyl compounds synthesis and reduction. Eur Confer Modell Simul 28:434-440 
15. Nielsen J, Villadsen J (1994) Bioreaction engineering principles. Plenum Press, New York

16. Olivier B (2001) Mass balance modelling of bioprocesses Comore. Inria, France

17. Parcunev I, Naydenova V, Kostov G, Yanakiev Y, Popova Z, Kaneva M, Ignatov I (2012) Modelling of alcoholic fermentation in brewing - some practical approaches. Eur Confer Modell Simul 26:434-440

18. Pontryagin LS (1962) Mathematical theory of optimal processes. Wiley, New York

19. Ramirez WF, Maciejowski J (2007) Optimal beer fermentation. J Inst Brew 113(3):325-333

20. Saerens SMG, Verbelen PJ, Vanbeneden N, Thevelein JM, Delvaux FR (2008) Monitoring the influence of high-gravity brewing and fermentation temperature on flavour formation by analysis of gene expression levels in brewing yeast. Appl Microbiol Biotechnol 80(6):760-780

21. Shuler M, Kargi F (2002) Bioprocess engineering basic concepts, 2nd edn. Prentice Hall, Saddle River

22. Verbelen PJ, Saerens SMG, Van Mulders SE, Delvaux F, Delvaux FR (2009) The role of oxygen in yeast metabolism during high cell density brewery fermentations, Appl Microbiol Biotechnol 82:760-789

23. Yu L, Wensel PC, Ma J, Chen S (2013) Mathematical modeling in anaerobic digestion (AD). J Bioremed Biodeg S 4:003. https:// doi.org/10.4172/21556199.S4-003

Publisher's Note Springer Nature remains neutral with regard to jurisdictional claims in published maps and institutional affiliations. 